\title{
NOVEL CURRENT-CONVEYOR-BASED SINGLE- ELEMENT-CONTROLLED OSCILLATOR EMPLOYING GROUNDED RESISTORS AND CAPACITORS
}

\author{
MUHAMMAD TAHER ABUELMA'ATTI AND ABDALLAH \\ AL-ALI AL-GHUMAIZ \\ King Fahd University of Petroleum and Minerals, Box 203, Dhahran 31261, Saudi Arabia
}

(Received May 31, 1994; in final form June 21, 1994)

\begin{abstract}
A novel single-element-controlled oscillator using two negative first-generation current-conveyors, two grounded capacitors and three grounded resistors is presented. The proposed circuit enjoys independent oscillation control through a single grounded resistor and independent frequency control through a single grounded resistor or a single grounded capacitor.
\end{abstract}

\section{INTRODUCTION}

In a recent letter, Chang [1] proposed a single-resistance-controlled current-conveyor-based oscillator. The proposed circuit used three grounded resistors and two grounded capacitors and enjoyed independent oscillation and frequency control. However, the major disadvantage of the circuit was the use of three current conveyors, two of them were positive second-generation current-conveyors $(\mathrm{CCII}+$ ) and the third was a negative first-generation current-conveyor $(\mathrm{CCI}-)$.

The purpose of this letter is to propose a novel current-conveyor-based singleelement controlled oscillator using only two $\mathrm{CCI}-$, three grounded resistors, and two grounded capacitors. The circuit enjoys independent control of oscillation and frequency and can be easily converted to a voltage-controlled oscillator.

\section{PROPOSED CIRCUIT}

The proposed circuit is shown in Fig. 1. Assuming ideal CCI - with $\mathrm{v}_{\mathrm{x}}=\mathrm{v}_{\mathrm{y}}, \mathrm{i}_{\mathrm{x}}=$ $\mathrm{i}_{\mathrm{y}}=\mathrm{i}_{\mathrm{z}}$, routine analysis shows that the characteristic equation of the circuit can be expressed as

$$
\mathrm{s}^{2} \mathrm{C}_{1} \mathrm{C}_{2}+\mathrm{sC}_{2}\left(\mathrm{G}_{1}-\mathrm{G}_{4}\right)+\mathrm{G}_{3} \mathrm{G}_{4}=0
$$




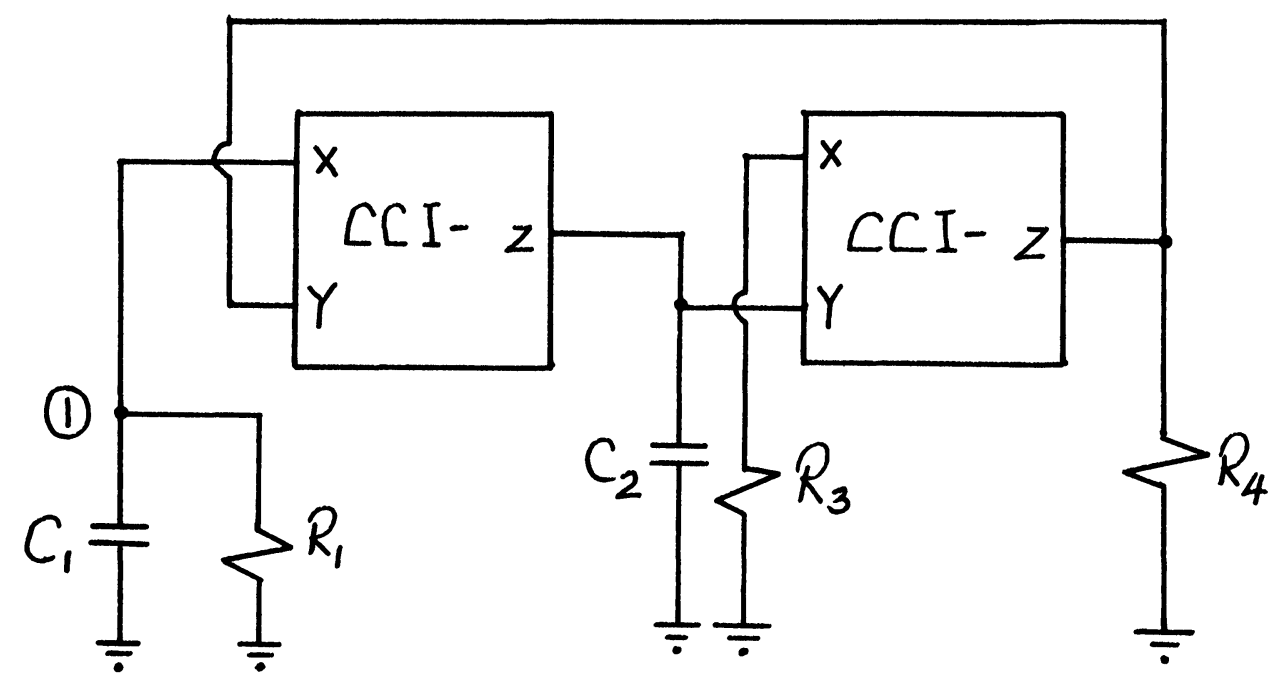

FIGURE 1 Proposed oscillator circuit.

Using (1), the condition of oscillation and the frequency of oscillation can be expressed as

$\omega_{0}^{2}=\frac{1}{\mathrm{C}_{1} \mathrm{C}_{2} \mathrm{R}_{3} \mathrm{R}_{4}}$

and

$\mathbf{R}_{1}=\mathbf{R}_{4}$

From (2) and (3), it is easy to see that the frequency of oscillation can be adjusted by tuning $R_{3}$ or $C_{1}$ or $C_{2}$ without disturbing the condition of oscillation while the condition of oscillation can be adjusted by tuning $R_{1}$ without disturbing the frequency of oscillation. Thus, the circuit enjoys independent oscillation and frequency control. By defining the passive sensitivity of a parameter $F$ to the element of variation $\mathrm{x}_{\mathrm{i}}$ by

$\mathrm{S}_{x_{\mathrm{i}}}^{\mathrm{F}}=\frac{\mathrm{dF}}{\mathrm{dx}_{\mathrm{i}}} \frac{\mathrm{x}_{\mathrm{i}}}{\mathrm{F}}$

it is easy to show that the sensitivity of the frequency of oscillation $\omega_{0}$ to the variation in passive elements is given by

$\mathrm{S}_{\mathrm{C}_{1}}^{\omega_{0}}=\mathrm{S}_{\mathrm{C}_{2}}^{\omega_{0}}=\mathrm{S}_{\mathrm{R}_{3}}^{\omega_{0}}=\mathrm{S}_{\mathrm{R}_{4}}^{\omega_{0}}=-\frac{1}{2}$

Thus, the $\omega_{0}$-sensitivity to passive elements is low. 


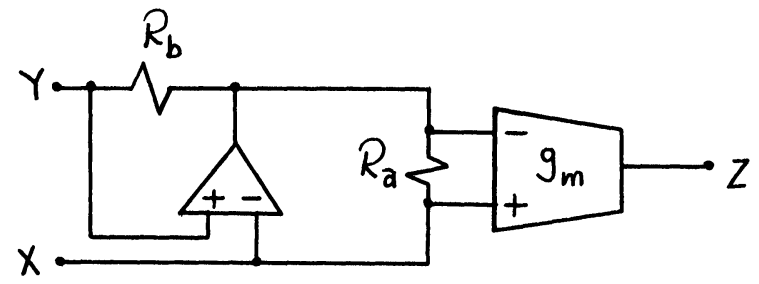

FIGURE 2 The CCI - realization proposed by Senani [2], $\mathrm{R}_{\mathrm{i}}=\mathrm{R}_{\mathrm{b}}, \mathrm{g}_{\mathrm{m}} \mathrm{R}_{\mathrm{i}}=1$.

\section{SIMULATION RESULTS}

The proposed circuit was simulated using PSpice Student Version 5.0. Although there were several ways to simulate the current-conveyors required, the simulation was performed using the circuit proposed by Senani [2] because of its simplicity. The kernel of the work presented in this letter was independent of the particular simulation selected. The CCI - was simulated using one operational amplifier and one operational transconductance amplifier and two resistors, shown in Fig. 2. The

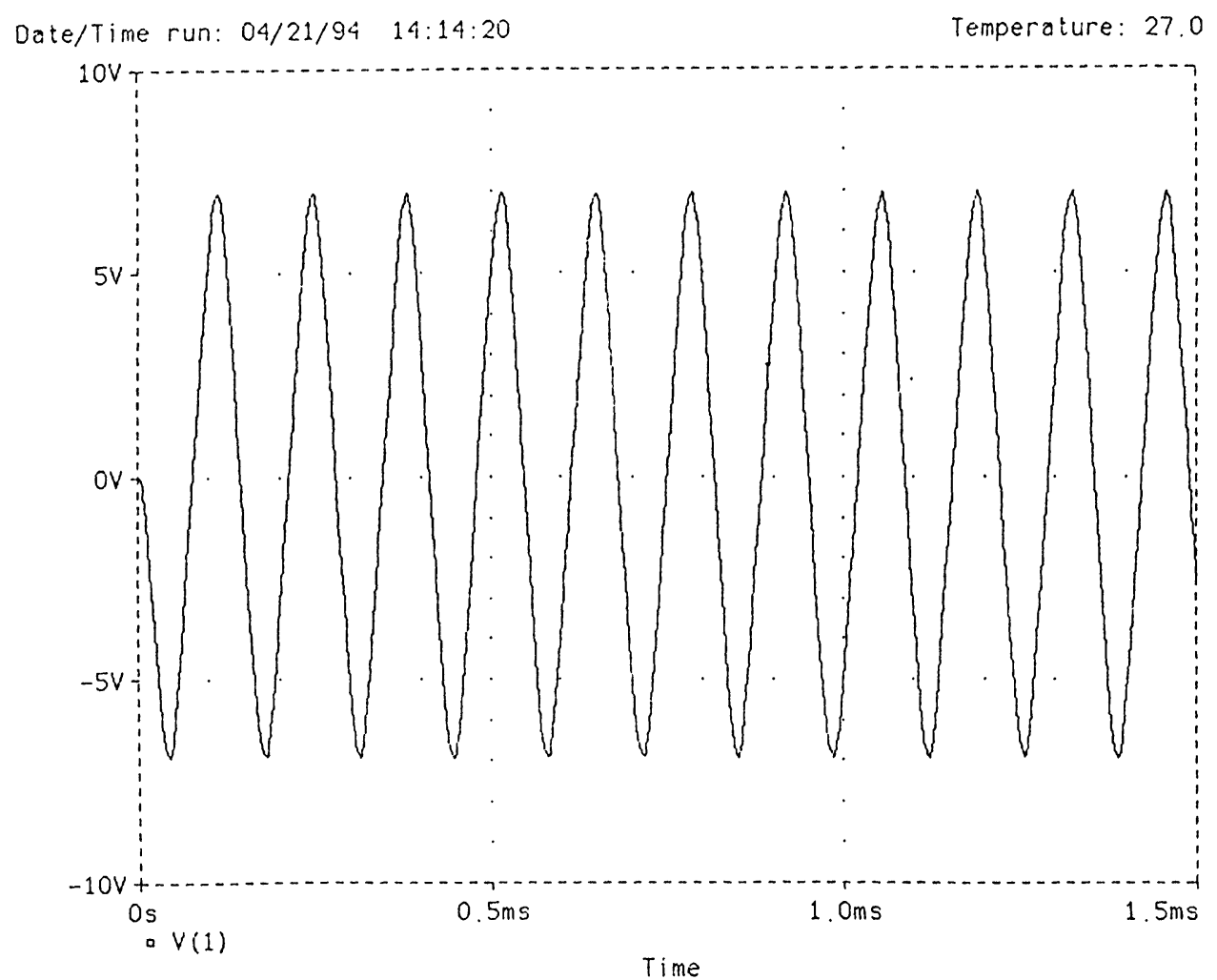

FIGURE 3 Simulated oscillation obtained from the circuit of Fig. 1 with $R_{1}=1.2 \mathrm{~K}, R_{3}=R_{4}=1 \mathrm{~K}$, $C_{1}=C_{2}=0.01 \mu \mathrm{F}$ and the $\mathrm{CCI}-$ parameters are: $\mathrm{R}_{\mathrm{i}}=\mathrm{R}_{\mathrm{b}}=1 \mathrm{~K}, \mathrm{~g}_{\mathrm{m}}=1 \mathrm{~mA} / \mathrm{V}$. 
operational amplifier was simulated using the uA741 model contained in the file called EVAL.LIB available in the PSpice student version. The start of the oscillation was caused by the offset voltage of the operational amplifier [3]. To demonstrate that the oscillations were self starting, the voltages across the capacitors were initialized at zero values. The operational transconductance amplifier was simulated assuming a finite input resistance of $2 \mathrm{Mohm}$. To avoid the possible latch-up resulting from the non-zero offset current at terminal $\mathrm{Z}$ of the current conveyors, an antiparallel diode pair was connected between terminal $\mathrm{Z}$ and the ground. Fig. 3 shows the simulated oscillation obtained from the circuit of Fig. 1 with

$\mathrm{R}_{1}=1.2 \mathrm{~K}, \mathrm{C}_{1}=\mathrm{C}_{2}=0.01 \mu \mathrm{F}, \mathrm{R}_{3}=\mathrm{R}_{4}=1 \mathrm{~K}$

The simulation results appear to be in good agreement with the presented theory.

\section{CONCLUSION}

In this letter, a novel current-conveyor-based oscillator has been presented. The circuit uses two negative first-gentration current conveyors, three grounded resistors, and two grounded capacitors. The circuit enjoys low sensitivities to passive components and independent control of the frequency and the condition of oscillation. The use of grounded capacitors makes the circuit attractive for integration, and the use of grounded resistors for independent control of the frequency of oscillation makes the circuit attractive for the realization of voltage controlled oscillators. Another attractive feature of the circuit is the use of two similar current conveyors. Thus, the circuit appears to be very attractive for integration.

\section{REFERENCES}

1. C.-M. Chang. Novel current-conveyor-based single-resistance-controlled/voltage-controlled oscillator employing grounded resistors and capacitors. Electronics Letters. Vol. 30, 1994, pp. 181-183.

2. R. Senani. Novel circuit implementation of current conveyors using O.A. and and an O.T.A. Electronics Letters, Vol. 16, 1980, pp. 2-3.

3. G.W. Roberts and A.S. Sedra. SPICE for Microelectronics. Saunders College Publishing, 1992. 

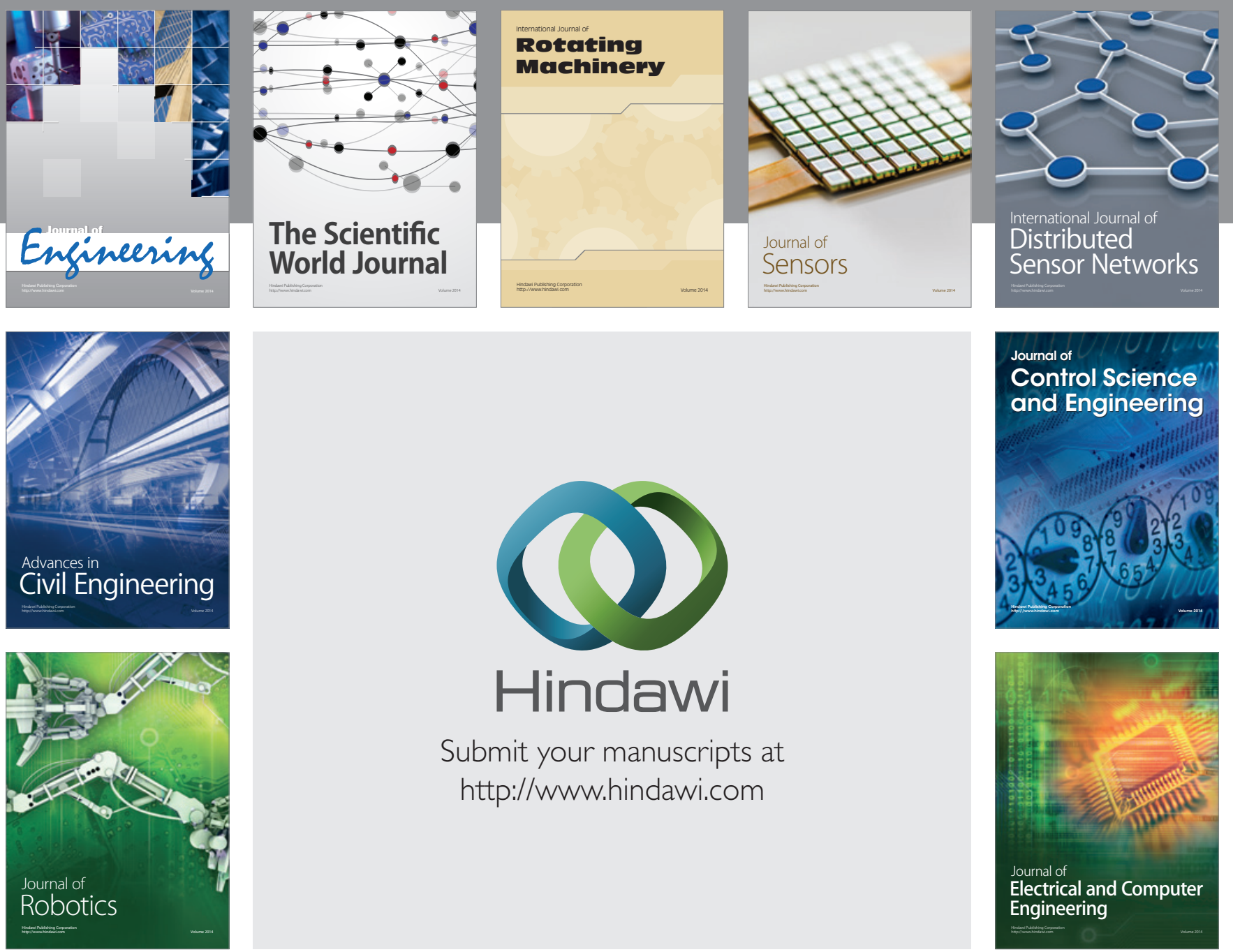

Submit your manuscripts at

http://www.hindawi.com
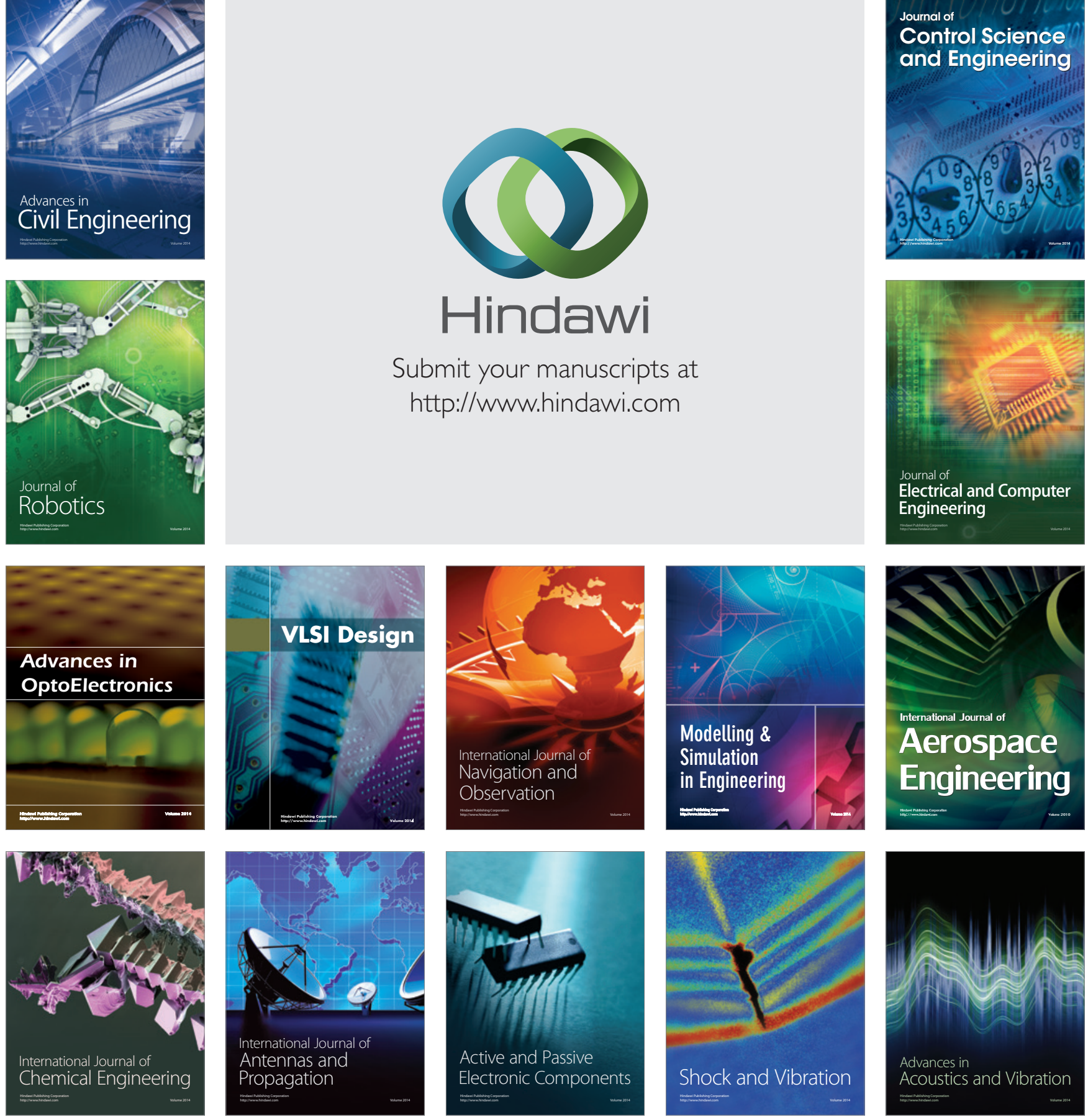